\title{
Polarisation, uncertainty and public investment failure
}

\author{
Frank Bohn* \\ Radboud University Nijmegen, Department of Economics (Thomas van Aquinostraat 5.1.14), \\ P.O. Box 9108, 6500 HK Nijmegen, The Netherlands
}

Received 21 March 2006; received in revised form 28 November 2006; accepted 30 November 2006

Available online 22 January 2007

\begin{abstract}
In a political economy model, the effect of political polarisation on a government's intertemporal choice between redistribution and public investment is shown to be similar to the effect of political uncertainty. Moreover, polarisation and uncertainty reinforce one another in their impact on public underinvestment and may ultimately lead to no investment at all.

(C) 2006 Elsevier B.V. All rights reserved.

JEL classification: $\mathrm{E} 62 ; \mathrm{O} 23$

Keywords: Political instability; Clientelism; Ethno-linguistic fractionalisation; Public finance; Political economy; Developing countries
\end{abstract}

\section{Introduction}

Political polarisation captures the phenomenon that societies are not homogeneous, but made up of different groups, which are often competing for political influence. Such heterogeneity can be based on ethnic, linguistic, religious diversity, income distribution and/or other social characteristics. Abstracting from the specific type of heterogeneity I model polarisation as the degree, to which the government favours one group over another, i.e. the degree, to which the heterogeneity actually matters for decision making. In a political economy model I can show that polarisation has similar effects as political uncertainty (government's chance of losing power) in producing public underinvestment. Probably the most important result is that polarisation and political uncertainty reinforce one another in their effect on underinvestment. Ultimately, this may lead to total public investment failure. This finding helps explain, for instance, that many

* Tel.: +312436 15507; fax: +31243612379.

E-mail address: f.bohn@fm.ru.nl. 
developing countries, especially in sub-Saharan Africa, suffer from poor public services in health, education, infrastructure, etc. despite large public expenditure (Pradhan, 1996).

The effects of political uncertainty (sometimes called political instability) are well documented in the model-theoretic literature. Most papers are two-period models. The chance of a change of decision maker who might take different, less desirable, decisions in the second period produces a negative spill-over onto the incumbent decision maker in the first period. Future outcomes and the effects of today's actions onto the future are more heavily discounted. In Cukierman et al. (1992), for instance, the result is higher seigniorage revenue today instead of economic reform effective tomorrow, in Devereux and Wen (1998), it is higher public activity and lower growth. Tabellini and Alesina's (1990) median voter typically chooses to borrow from the future to pay for higher public goods spending today. ${ }^{1}$ However, none of these models disentangles the effects of polarisation from those of political uncertainty, even though agents have preferences over two types of public goods.

In contrast to political uncertainty, polarisation has only been scrutinised under specific circumstances. On the one hand, there is a lot of empirical evidence documenting the key role of political polarisation for growth collapse and development failures. ${ }^{2}$ Easterly and Levine (1997) find that, empirically, ethnic diversity is the single most important cause of slow growth in Africa. ${ }^{3}$ Collier and Gunning (1999) argue that ethnic diversity promotes ethnic favouritism, i.e. diverting public spending to ethnic groups instead of creating better conditions for the whole of society. ${ }^{4}$ On the other hand, there is the literature on clientelism. ${ }^{5}$ Robinson and Verdier (2002) analyse clientelism in a game-theoretic framework with an asymmetric political structure. It is optimal for patrons to invest too little in public services while overproviding public employment, which they demonstrate to be an "incentive-compatible way for patrons to control clients."6

This paper acknowledges that political uncertainty (chance of losing power) and polarisation (heterogeneity) are distinct empirical phenomena relevant for both developing and more developed countries. The political economy model I present abstracts from specific forms of polarisation or political uncertainty and captures directly the trade-off between redistribution and public investment. In an intertemporal public finance model with two rivaling groups, a government can choose between (efficient) public investment and spending on public goods, one of which is only beneficial to one group, the other is only useful to the other group. There is more or less redistribution depending on how much the government prefers one public good over the

\footnotetext{
${ }^{1}$ Darby et al. (2004) include public investment, but - due to the specific functional format of their production function they cannot obtain the instability threshold obtained in this paper.

${ }^{2}$ A whole range of empirical explanations and verbal (sometimes anecdotal) arguments are offered by, for instance, Easterly and Levine (1997), Collier and Gunning (1999), Easterly (2001), Hillman (2002), and Gupta et al. (2005).

${ }^{3}$ More specifically, Collier (1998) claims that the negative effect of ethnic diversity on growth is only true for undemocratic countries.

${ }^{4}$ According to a biopolitical study by Tatu Vanhanen (1999), it is natural to the human race to favour kin over nonkin. Discussing "the post-colonial political inheritance" of African countries, Rowley (2000) points out that "the battle for control over the apparatus of government assumed an importance out of all proportion to Western experience as tribes, ethnic groups, and regional interest groups vied for the rents that political control was seen to offer".

5 Kurer (1993) describes it as follows: "The actors in the model are patrons, clients and non-clients. The patrons are the politicians in power who determine the size and the distribution of government revenue. The clients elect and support their patron politically in return for economic benefits derived from the association with the patron. Class, corporation, or ideology do not influence the behaviour of the clients." Bratton and van de Walle (1994) explain why clientelism (in their terminology neopatrimonialism) hampers the political evolution in Africa.

${ }^{6}$ Robinson and Torvik (2005) obtain a similar result in a different, non-clientelistic model with efficient and inefficient public investment, but no public consumption. They also show that political uncertainty creates incentives to invest in inefficient public works projects.
} 
other (polarisation). However, the incumbent faces an exogenous chance of losing power to the opposition with different preferences (political uncertainty). ${ }^{7}$

The new insight I derive is that polarisation and uncertainty are mutually dependent in their effect on public investment. The reason is that it is perfectly rational for a government to invest less in period 1 when beneficial effects of its policies may not fully accrue to it in the future. The incumbent government is effectively discounting the future more heavily in the presence of polarisation and uncertainty. If the alternative government is known to favour the other group (polarisation), political uncertainty will cause underinvestment because public investment will be used for achieving other objectives in case of government change. However, in the extreme case of no polarisation at all, political uncertainty has no effect because the other government would pursue identical policies in the future anyway. Similarly, if the government stays in power with certainty, it is irrelevant, if there is a lot of polarisation or not. Furthermore, it is shown that polarisation and uncertainty reinforce one another in their effect on public underinvestment. Typically, there is a threshold, beyond which the government does not want to invest at all. Reducing polarisation and political uncertainty above the threshold and thereby effectively discounting the future less severely leads to a strong increase in public investment at first. However, the additional investment increments (for less and less polarisation and uncertainty) become smaller because marginal investment profitability goes down.

Section 2 presents the intertemporal framework of the theoretical model. In Section 3, the government's maximisation problem is simplified by aggregating polarisation and uncertainty into a composite measure of political instability. Section 4 presents the interior solution for aggregate political instability. Section 5 discusses the danger of public investment failure by emphasising how polarisation and uncertainty reinforce one another and by presenting the corner solution of no public investment at all. Section 6 concludes.

\section{Political model of public investment}

The model consists of two periods and two sectors, the government (types $f$ and $g$ ) and the private sector. The model is specified in real terms. For incumbent government $f$, preferences over periods 1 and 2 are given by the following utility function (analogously for government $g$ ):

$$
W^{f}=V_{1}\left(C_{1}\right)+H_{1}^{f}\left(G_{1}^{f}, F_{1}^{f}\right)+E\left\{\rho\left(V_{2}\left(C_{2}\right)+H_{2}^{f}\left(G_{2}^{f}, F_{2}^{f}\right)\right)\right\} .
$$

The $V .(\bullet)$ functions are concave and twice continuously differentiable utility functions of the government in private sector consumption $C$ (identical for both governments). The $H^{f}(\bullet)$ functions are the utility functions in government $f$ 's provision of the amounts of two public goods $F$ and $G$ in both periods. $F$ is beneficial only to one group in society and $G$ exclusively to the other. The quantities of provision of $F$ and $G$ could be interpreted as redistribution or as vested interest rents due to state capture or nepotism. More specifically, government $f$ could be seen as representing the interests of the group benefitting from $F$, whereas government $g$ may be associated with the other group. The two groups could be two (of possibly more) tribes, regional

\footnotetext{
${ }^{7}$ Similar to Cukierman et al. (1992), Devereux and Wen (1998), Svensson (1998) or Bohn (2004, 2006), I model political uncertainty by an exogenous parameter. I abstract from electoral processes (democracies), or causal explanations for revolutions and coup d'états (autocracies). An explicit theory of insurrections was developed by Herschel Grossman, but it cannot account for the intertemporal links needed here. The probability of success of an insurrection is either exogenous (for instance, Grossman, 1991), due to investment in fighting strength (Grossman, 1999), or depends on "rentreducing economic reforms" (McBride, 2005).
} 
interest groups or social or ethnic groups or just two family clans. $E$ is the expectation operator and $\rho<1$ is the government's discount factor.

There is political uncertainty and polarisation. After the first period the incumbent government may lose office to the other government with a fixed probability $\pi$; it stays in power with probability $(1-\pi)$. Each of the two types of government $(f$ and $g$ ) provides both types of public goods, but to differing degrees. Political polarisation then depends on the differences of governments' preferences with respect to their public goods provision as expressed by their respective public goods utility functions $H^{f}$ and $H^{g}$ :

$$
\begin{array}{ll}
H^{f}\left(F^{f}, G^{f}\right)=\min \left[\frac{F^{f}}{\alpha^{f}}, \frac{G^{f}}{1-\alpha^{f}}\right], & 1>\alpha^{f} \geq \frac{1}{2}, \\
H^{g}\left(F^{g}, G^{g}\right)=\min \left[\frac{F^{g}}{1-\alpha^{g}}, \frac{G^{g}}{\alpha^{g}}\right], & 1>\alpha^{g} \geq \frac{1}{2} .
\end{array}
$$

Exogenous parameter $\alpha^{f}$ captures the relative weight government $f$ places on the provision of $F$ rather than $G$. As $\alpha^{f}$ increases, government $f$ wants its own group to benefit more (and analogously for government $g$, if $\alpha^{g}$ rises). For simplicity, the two governments' disagreement in public goods provision is parameterised symmetrically, i.e. $\alpha^{f}=\alpha^{g}=: \alpha$. A convenient property of the $H^{f}(\bullet)$ function is that the public goods utility (for government $f$ 's optimal choice of relative quantities of the two public goods) equals $X^{f}$, defined by the sum of spending on both public goods: $H^{f}\left(G^{f}, F^{f}\right)=X^{f}:=F^{f}+G^{f}$. . Analogously for the $H^{g}(\bullet)$ function. In each case, the marginal public goods utility is unity.

The specification in Eq. (2) is as general as possible to capture a wide range of cases. The more distant $\alpha$ is from half, the more the two governments disagree on how much to spend on each of the two public goods. If preferences of both government types are very dissimilar, political polarisation is large and policies would change considerably in case the incumbent lost power in the second period. The extreme clientelist model is described by $\alpha$ very close to 1 . Irrespective of which government is in power, basically only one of the two groups, i.e. the patron's clients, is supplied with public goods (the other group only receives a minute amount): government $f$ supplies good $F$ almost exclusively, whereas it is good $G$ with government $g$ in power. When $\alpha$ equals half, the two types of government have identical preferences. This could be interpreted as an extreme case of a consensual society, for instance, in a democracy where left and right wing parties compete about the votes in the centre. In this case, a change of government does not matter at all.

The government budget constraints in real terms for both model periods (1 and 2) are:

$$
\begin{aligned}
& I+G_{1}+F_{1} \leq \tau \bar{Y} . \\
& G_{2}+F_{2} \leq \tau Y(I) .
\end{aligned}
$$

Government expenditure consists of two kinds: public investment $I$; and consumptive spending $F$ and $G$, which is spent on the two types of public goods. As in Aghion and Bolton (1990) tax

\footnotetext{
${ }^{8}$ Optimality in minimum function (2) can only be achieved for $F^{f} / \alpha=G^{f} /(1-\alpha)$. Hence $X^{f}:=F^{f}+G^{f}=(1 / \alpha) F^{f}$ (or $=$ $\left.(1 /(1-\alpha)) G^{f}\right)$. Then $G^{f}=(1-\alpha) X^{f}$ and $F^{f}=\alpha X^{f}$ can be replaced in Eq. (2).
} 
revenues are calculated from constant tax rate $\tau$ and income as tax base. The tax rate and first period income $\bar{Y}$ (an endowment) are exogenous, but second period income $Y(I)$ depends on public investment $I$ in the previous period with $Y^{\prime}(I)>0, Y^{\prime \prime}(I)<0$.

The private sector budget constraints in real terms for both periods are simply:

$$
\begin{aligned}
& C_{1} \leq(1-\tau) \bar{Y} . \\
& C_{2} \leq(1-\tau) Y(I) .
\end{aligned}
$$

Each period real private consumption depends on real income net of non-distortionary taxes. The model could be interpreted in per capita terms, but the private sector is passive in the sense that it cannot take optimising decisions on labour, savings or private investment. Thus, the two private sector budget constraints are not directly linked intertemporally. In that regard the model is similar to Cukierman et al. (1992). Income growth is only generated by public investment, not by private sector activity. These assumptions allow us to focus on the government and its decision problem. They may be justified in two ways: first, this is a short run model; and, second, growth in lowincome countries is largely determined by factors like (infra-) structural or other public investment (as modeled here) or foreign direct investment (which is not captured in the model). As there is no private investment in the model, the terms "public investment" and "investment" are henceforth used interchangeably.

\section{Aggregate political instability}

The government has two types of instruments to increase its utility: public investment in period 1 and public spending on each of the two public goods in both periods. Increasing this period's public spending raises contemporaneous public goods utility $H$. Higher investment this period increases future private sector income (and thereby private sector utility) as well as tax revenues (and thereby public goods spending and utility) in the following period. Investment and the intertemporal distribution of total public goods spending are determined by (i) the discount factor (reduced by political uncertainty and polarisation as shown in Eq. (5)); and (ii) the profitability of public investment (i.e. the shape of the $Y(I)$ function).

Public goods utility $H$ (Eq. (2) under symmetry assumption $\alpha^{f}=\alpha^{g}=\alpha$ ) has specific implications for the optimal choice by two alternative governments $f$ and $g$. First, public goods utility $H$ derived from type $f^{\prime}$ 's choice of $F$ and $G$ (when in power) is equal to the public goods utility derived from type $g$ 's choice (when in power): $H^{f}\left(G^{f}, F^{f}\right)=G^{f}+F^{f}=X^{f}=X=X^{g}=G^{g}+F^{g}=H^{g}\left(G^{g}, F^{g}\right)$. Second, government $g$ 's optimal choice for $F$ and $G$ is, of course, suboptimal for government $f$ : $X^{f}=H^{f}\left(G^{f}, F^{f}\right)>H^{f}\left(G^{g}, F^{g}\right)=((1-\alpha) / \alpha) X^{f}$.

The government in power in period 1 chooses the quantity of the public goods in period 1 , but it can only choose in period 2 if it does not lose power, in which case the rivaling government takes the decision. Utility function (1) becomes:

$$
\begin{aligned}
W & =V\left(C_{1}\right)+X_{1}+\rho\left[(1-\pi)\left(V\left(C_{2}\right)+X_{2}\right)+\pi\left(V\left(C_{2}\right)+\frac{1-\alpha}{\alpha} X_{2}\right)\right] \\
& =V\left(C_{1}\right)+X_{1}+\rho\left[V\left(C_{2}\right)+\beta(\alpha, \pi) X_{2}\right]
\end{aligned}
$$


Note that $\beta(\alpha, \pi)$ augments the effect of government discount factor $\rho$ : it lowers the valuation for public goods spending in the second period. Composite measure $\beta$ is henceforth called (aggregate) political instability:

$$
0<\beta(\alpha, \pi)=(1-\pi)+\pi \frac{1-\alpha}{\alpha} \leq 1
$$

Obviously, $\beta=1$ if both governments have identical preferences $(\alpha=1 / 2)$ or if the government stays in power with certainty $(\pi=0)$. For $\alpha=1$ (but it can only be close to 1 ) and $\pi=1, \beta$ would be 0 . In other words, $\beta$ decreases with more political diversity (polarisation $\alpha \uparrow$ ) and/or more political uncertainty (probability of government change $\pi \uparrow$ ).

Eq. (5) shows that total public goods utility does not depend on the optimal distribution of public goods spending between $F$ and $G$, but on its total amount $X$. Nor does it depend on which government is in power. Nonetheless, the fact that there are two potential governments does have crucial implications for any government decision on the total amount of public goods spending as well as on public investment, because aggregate political instability reduces the discount factor. In fact, the model is constructed that way to allow for the analysis of aggregate political instability by itself (as, for instance, in Cukierman et al., 1992; Svensson, 1998) as opposed to analysing the effect of different types of government with different objectives (as, for instance, in Aghion and Bolton, 1990; Tabellini and Alesina, 1990).

\section{Result 1: underinvestment under political instability}

The government's decision problem can now be specified on the basis of utility function (5) with budget constraints (3) and (4) substituted in for $X_{t}$ and $C_{t}, t=1,2$, respectively:

$$
\max _{I} V((1-\tau) \bar{Y})+\tau \bar{Y}-I+\rho V((1-\tau) Y(I))+\rho \beta(\alpha, \pi) \tau Y(I)
$$

The first order condition (FOC) with respect to the (remaining) policy variable $I$ is as follows:

$$
-1+\rho V^{\prime}((1-\tau) Y(I))\left((1-\tau) Y^{\prime}(I)\right)+\rho \beta(\alpha, \pi) \tau Y^{\prime}(I)=0
$$

The FOC requires that the marginal utility of (giving up 1 unit of) public goods provision in period 1 (which is unity due to assumption 2 on public goods utility $H$ ) must be equal to the marginal utility derived from (i) additional second period consumption (due to the after-tax income effect of increased investment) and (ii) additional public goods provision in period 2 (due to the tax effect of increased investment). Note that the discount factors for marginal utilities (i) and (ii) are different. As for (i), marginal utility $V^{\prime}$ is discounted by government discount factor $\rho$. As for (ii), unity marginal utility of the public goods provision is discounted by $\rho \beta$ (because the valuation of the public goods provision in period 2 is different for the two types of government).

Objective function (7) is strictly concave. An interior solution is, therefore, obtained, if $\partial W /$ $\partial I>0$ when evaluated at $I=0$, that is

$$
-1+\rho V^{\prime}((1-\tau) Y(0))(1-\tau) Y^{\prime}(0)+\rho \beta(\alpha, \pi) \tau Y^{\prime}(0)>0 .
$$

Under sufficiently extreme aggregate political instability ( $\beta$ close to 0$)$, i.e. strong polarisation and a lot of political uncertainty (confer Eq. (6)), inequality (9) is typically violated and we obtain a 
corner solution with no public investment at all. ${ }^{9}$ Above some critical value for $\beta, \beta>\beta^{*}$, an interior solution prevails. Ultimately, we are interested in the perturbation effect of aggregate political instability $\beta$ on optimal public investment $I$. Applying total differentials leads to

Proposition 1. Interior solution

For $\beta>\beta^{*}$, the following perturbation results hold at the equilibrium:
(i) $\frac{\mathrm{d} I}{\mathrm{~d} \beta}>0$ and
(ii) $\frac{\mathrm{d} \frac{\mathrm{d} I}{\mathrm{~d} \beta}}{\mathrm{d} \beta}<0$.

The Appendix outlines the derivation of Proposition 1. Point (i) states that increasing $\beta$, i.e. less aggregate political instability, at the equilibrium leads to more public investment (as long as $\beta>\beta^{*}$ ). Additional political stability effectively increases the discount factor for the future. As the government values the second period more, it is optimal to invest more into the future. This is intuitive and straightforward. Point (ii) of Proposition 1 asserts that the (positive) marginal effect on investment of more political stability decreases. This is so because the marginal investment profitability goes down. Conversely, Proposition 1 means that a marginal increase in aggregate political instability at the equilibrium leads to a depletion of public investment, which accelerates for higher values of instability (up to $\beta^{*}$ ).

It seems straightforward to call public investment below the level obtained for $\beta=1$ underinvestment. After all, $\beta=1$ can be produced by eliminating political uncertainty (i.e. $\pi=0$, which means that the government stays in power with certainty). Getting rid of distortionary discounting implies an increase in welfare. From the perspective of a politically stable country (no polarisation and/or no uncertainty), lower investment always leads to a reduction in welfare. However, $\beta$ can also be seen to reflect de facto polarisation $(\beta<1$ is obtained for $\alpha>1 / 2$, i.e. some degree of polarisation). Then the underinvestment and welfare interpretations are not so straightforward and depend upon the welfare metric applied, which is, of course, always somewhat arbitrary. By using a peculiar welfare metric and/or unusual functional formats for the investment and utility functions, it might be possible to raise investment by increasing $\beta$ without improving welfare.

Nonetheless, welfare improvements for increased political stability (and hence raised investment) can be demonstrated for a whole range of more standard cases. For instance, if we measure welfare purely in terms of utility from private consumption (Eq. (4)), then more political stability is beneficial as increased public investment raises future output and hence future consumption utility without affecting today's utility. This is at the expense of spending on specific groups. This welfare metric is particularly suitable, if we interpret such spending as state capture or nepotism. But even if we focus on the well-being of those (vested interest) groups, increasing political stability will typically lead to welfare improvements. Consider a simplified model where the government is purely interested in public goods utility function $H$ (Eq. (2)) in both periods. If that government objective function is then also used as welfare metric, the welfare-improvement property can be demonstrated for several classes of investment functions (including square root and logarithmic).

\footnotetext{
${ }^{9}$ The second term in condition (9) is smaller than 1 , if $Y^{\prime}(0)$ is not extremely large and $V^{\prime}<1=H^{\prime}$. The latter is suggested by Esfahani (2000) and follows Rowley's (2000) evaluation of the significance of the political culture of conflict and the struggle over redistribution in Africa.
} 


\section{Result 2: danger of public investment failure}

Subsuming $\alpha$ and $\pi$ under $\beta$ was convenient for the mathematical derivation of Proposition 1 . To further exploit the interior solution finding, it is, however, useful to disentangle the components of $\beta$ in

Proposition 2. Political acceleration effects

Polarisation $\alpha$ and political uncertainty $\pi$ accelerate one another in their effect on underinvestment. The political instability effect produced by each one of the two components of aggregate political instability $\beta$ is increasing in the other component:
(i) $\frac{\partial \beta}{\partial \pi}=-2+\frac{1}{\alpha} \leq 0$ and
(ii) $\frac{\partial \beta}{\partial \alpha}=-\frac{\pi}{\alpha^{2}} \leq 0$.

We already know from Eq. (6) that there is a negative marginal effect of $\pi$ on $\beta$, unless $\alpha=1 / 2$ (when $\partial \beta / \partial \pi=0$ ). However, point (i) also shows that the negative marginal effect increases in $\alpha$. Remember that lower $\beta$ (more aggregate political instability) effectively reduces the discount factor. Thus more polarisation accelerates the effect of political uncertainty. According to point (ii), the reverse is also true: more political uncertainty magnifies the impact of political polarisation. Note, however, (in (i)) that $\beta$ and hence investment are not affected by a change in political uncertainty, if there is no polarisation at all $(\alpha=1 / 2)$. Nor is there (in (ii)) an effect due to a change in polarisation, if the government stays in power with certainty $(\pi=0)$.

If the government faces some chance of losing power and there is some polarisation, then an increase in either of them exacerbates the shortfall of public investment. The effect is, however, magnified, if both of them deteriorate at the same time. Then, the negative effect on marginal investment becomes dramatic. This is so, until aggregate political instability threshold $\beta^{*}$ is reached. Public investment cannot be reduced at an ever increasing rate for increasing aggregate political instability ( $\beta$ decreased). If public investment is constrained to non-negative values in this two-period model, the optimal choice of the government is the corner solution.

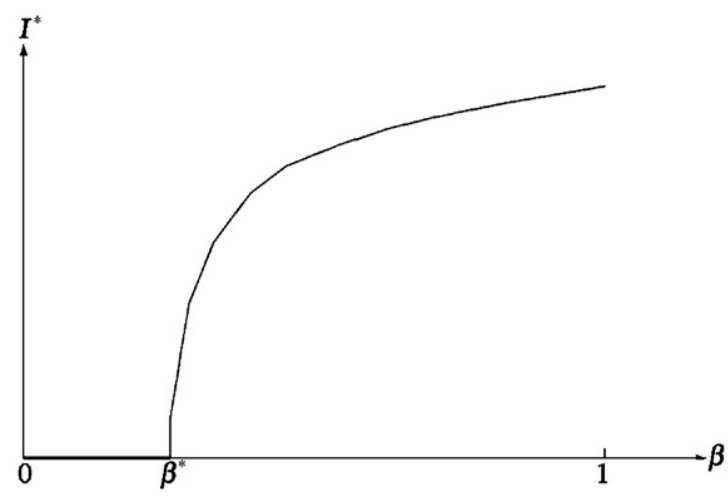

Fig. 1. Optimal public investment. 
Proposition 3. Corner solution

\section{For $\beta<\beta^{*}$, it is optimal for the government not to invest.}

The proposition appears obvious from first inspection of the problem, but can formally be proved using the Kuhn-Tucker conditions. The intuition is also simple. For small $\beta$, the government values the present much more than the future. Second period benefits from investment are discounted too heavily. The government does not want to move resources from today to tomorrow at all. Hence there is no investment. In the real world, disinvestment (like the sale of infrastructure, e.g. train coaches) might actually result from heavy discounting.

The perturbation results of Proposition 1 and the corner solution in Proposition 3 are summarised in Fig. 1. The graph depicts the optimal values for $I, I^{*}$, as a function of $\beta$ for its entire range $(0<\beta \leq 1)$. For small values of $\beta, I^{*}$ is zero. However, from $\beta=\beta^{*}$ onwards, it is optimal for the government to invest more and more for increasing $\beta$. The $I^{*}$ function is continuous, but non-differentiable at $\beta^{*}$. It is concave (and differentiable) thereafter. The marginal effect is discontinuous at $\beta=\beta^{*}$, where $\mathrm{d} I^{*} / \mathrm{d} \beta$ jumps to infinity, but (is differentiable and) decreases thereafter while remaining positive.

\section{Conclusion}

This paper captures a government's decision problem between efficient public investment and redistribution in a parsimonious model of political instability. The chance of another government being in power and taking undesirable decisions in the future produces a negative spill-over onto those in power today. In this paper, it is actually optimal for the current government to totally refrain from spending on public investment, if there is heavy discounting produced by political instability. As political stability increases (and discounting decreases), a threshold is reached, beyond which it is optimal to increase investment with marginal investment being strong at first. Then, however, the additional investment increments become smaller, because marginal investment profitability goes down.

The theoretical model captures the impact of two distinct causes of political instability as they appear in reality: polarisation (rivaling groups in society) and political uncertainty about the future government. Probably the most important result is that their effect on a government's effective discounting is multiplicative. Underinvestment in infrastructure, anti-corruption measures, health, or education is particularly severe in a country with a legacy of group-specific policies and numerous government changes. Therefore, the paper offers an explanation for appalling levels of efficient public investment in sub-Saharan African countries, which are troubled by ethnic strife combined with a history of coup d'états or revolutions. But the model may also help explain inefficient government sectors in unstable Western democracies such as France (during the Forth Republic) or Italy (before the break-up of the traditional party system in 1992).

Nonetheless, for several reasons the modeling approach seems to be particularly relevant for certain low-income countries. First, political uncertainty in some of these countries is inherent to the political structure of the country rather than caused by electoral uncertainty as in Western democracies. Capturing political uncertainty by an exogenous parameter may, therefore, be deemed more appropriate for such countries. Second, ethnic diversity is a real additional problem in many low-income countries. This means that polarisation is a much more clear-cut and severe problem than in Western democracies where the electoral process entices the parties to compete for the votes in the centre. Third, the disregard for private sector decisions on labour, consumption and investment would certainly not be suitable simplifications for industrialised countries, but 
may be seen as a first approximation in some low-income countries, where there is either no economic growth or it depends on external factors (like foreign direct investment).

Relaxing some of the assumptions of this paper may offer scope for future research. It may be worth while exploring if there are any trade-off effects when other sources of government revenue are included. Another extension would be to model the effect of public investment on growth, when the private sector optimises its investment and consumption decisions. A further extension might be to capture the interdependence between growth and political instability. So far, political instability was endogenised in the literature by modeling voting ${ }^{10}$ or by modeling insurgencies either in response to the relative military strengths of government and rebels (Grossman, 1999) or dependent upon "rent-seeking economic reforms" (McBride, 2005). However and particularly relevant for capturing the government decision problem in low-income countries: better economic conditions directly affect the chance of a coup d'état or revolution. For these countries, it seems appropriate, therefore, to capture the feedback of government actions on growth and model its interdependence with political instability. It would be interesting to explore the link to the literature on endogenous growth and rent-seeking such as Ehrlich and Lui (1999) or Park et al. (2005).

\section{Acknowledgements}

I am grateful for comments by my former colleague Ivan Pastine and participants at the Royal Economic Society Meetings and the European Public Choice Society Meetings. Three anonymous referees and one of the editors ensured that the paper improved significantly and focused on polarisation. All remaining errors are mine. Comments most welcome.

\section{Appendix: Perturbation results}

Proposition 1 (i) - given $\beta>\beta$ :

$$
\frac{d I}{d \beta}=-\frac{\frac{\partial W_{I}}{\partial \beta}}{\frac{\partial W_{I}}{\partial I}}=-\frac{\overbrace{\rho \tau Y^{\prime}(I)}^{+}}{\underbrace{\frac{\partial W_{I}}{\partial I}}_{-}}>0
$$

Proposition 1 (ii) - given $\beta>\beta$ :

$$
\frac{d \frac{d I}{d \beta}}{d \beta}=\frac{\overbrace{\left(-\rho \tau Y^{\prime \prime}(I) \frac{\partial W_{I}}{\partial I}\right)}^{-}-\overbrace{\left(-\rho \tau Y^{\prime}(I) \rho \tau Y^{\prime \prime}(I)\right)}^{+}}{\underbrace{\left(\frac{\partial W_{I}}{\partial I}\right)^{2}}_{+}}<0
$$

\footnotetext{
${ }^{10}$ For instance, Robinson and Torvik (2005) use probabilistic voting, whereas Tabellini and Alesina (1990) employ a median voter approach in their political instability model.
} 


\section{References}

Aghion, P., Bolton, P., 1990. Government domestic debt and the risk of default: a political-economic model of the strategic role of debt. In: Dornbusch, R., Draghi, M. (Eds.), Public Debt Management: Theory and History. Cambridge University Press, Cambridge, pp. 315-344.

Bohn, F., 2004. The trade-off between monetary and fiscal solidity: international lenders and political instability. Centre for Economic Research Working Paper 04/08. University College Dublin.

Bohn, F., 2006. Eliminating the inflationary finance trap in a politically unstable country: domestic politics versus international pressure. Economics and Politics 18, 71-94.

Bratton, M., van de Walle, N., 1994. Neopatrimonial regimes and political transitions in Africa. World Politics 46, 453-489.

Collier, P., 1998. The political economy of ethnicity. Paper Presented at the Annual Bank Conference on Development Economics. World Bank, Washington, D.C.

Collier, P., Gunning, J.W., 1999. Why has Africa grown slowly? Journal of Economic Perspectives 13, 3-22.

Cukierman, A., Edwards, S., Tabellini, G., 1992. Seigniorage and political instability. American Economic Review 82, $537-555$.

Darby, J., Li, C.-W., Muscatelli, A., 2004. Political uncertainty, public expenditure and growth. European Journal of Political Economy 20, 153-179.

Devereux, M.B., Wen, J.-F., 1998. Political instability, capital taxation, and growth. European Economic Review 42, $1635-1651$.

Easterly, W., 2001. The Elusive Quest for Growth: Economists’ Adventures and Misadventures in the Tropics. MIT Press, Cambridge, MA.

Easterly, W., Levine, R., 1997. Africa's growth tragedy: policies and ethnic divisions. Quarterly Journal of Economics 1203-1250.

Ehrlich, I., Lui, F.T., 1999. Bureaucratic corruption and endogenous economic growth. Journal of Political Economy 107, S270-S293.

Esfahani, H.S., 2000. Institutions and government controls. Journal of Development Economics 63, $197-229$.

Grossman, H.I., 1991. A general equilibrium model of insurrections. American Economic Review 81, 912-921.

Grossman, H.I., 1999. Kleptocracy and revolutions. Oxford Economic Papers 51, 267-283.

Gupta, S., Clements, B., Baldacci, E., Mulas-Granados, C., 2005. Fiscal policy, expenditure composition, and growth in low-income countries. Journal of International Money and Finance 24, 441-463.

Hillman, A., 2002. The World Bank and the persistence of poverty in poor countries. European Journal of Political Economy 18, 783-795.

Kurer, O., 1993. Clientelism, corruption, and the allocation of resources. Public Choice 77, 259-273.

McBride, M., 2005. Crises, reforms, and regime persistence in sub-Saharan Africa. European Journal of Political Economy 21, 688-707.

Park, H., Philippopoulos, A., Vassilatos, V., 2005. Choosing the size of the public sector under rent seeking from state coffers. European Journal of Political Economy 21, 830-850.

Pradhan, S., 1996. Evaluating public spending. World Bank Discussion Paper 323. World Bank, Washington D.C.

Robinson, J.A., Torvik, R., 2005. White elephants. Journal of Public Economics 89, 197-210.

Robinson, J.A., Verdier, T., 2002. The political economy of clientelism. Centre for Economic Policy Research (CEPR) Discussion Paper 3205, London.

Rowley, C.K., 2000. Political culture and economic performance in sub-Saharan Africa. European Journal of Political Economy 16, 133-158.

Svensson, J., 1998. Investment, property rights and political instability: theory and evidence. European Economic Review 42, 1317-1341.

Tabellini, G., Alesina, A., 1990. Voting on the budget deficit. American Economic Review 80, 37-49.

Vanhanen, T., 1999. Ethnic conflicts explained by ethnic nepotism. Research in Biopolitics, vol. 7. JAI Press, Stamford CT. 